\title{
FUNCTIONAL SCHEMES FOR BIOMASS USE IN AUTONOMOUS HEAT POWER COMPLEXES OF KALININGRAD REGION
}

\author{
Elena Berkova \\ Viktor Selin \\ Kaliningrad State Technical University, Russia
}

\begin{abstract}
Energy deficiency of Kaliningrad region compels to look for the ways of using non-traditional and renewable energy resources in the regional energy balance. One of the perspective resources is biomass which includes wood waste of forestry activity, solid domestic waste and combustible industrial refuse, wastes of animal husbandry, poultry breeding and plant growing and etc. Based on preliminary estimation, biofuel can replace more than 85,000 tons of equivalent fuel per year. Functional scheme of autonomous heat power complexes for Kaliningrad region was worked out. Resource base of these complexes will be large-scale agroindustial enterprises, poultry factories, fur farms, timber enterprises and small individual farms. At such objects different organic waste materials of animal and plant origin will be subjected to ecological clean without waste processing with the production of biogas, natural fertilizers, heat energy and electricity. Combination of biogas units with wind energy turbines, solar collectors and heat pumps will allow complete application of traditional fuel and energy resources.
\end{abstract}

\section{KEYWORDS}

Functional schemes; Autonomous heat power complexes; Organic waste; Biogas; Biomass.

\section{INTRODUCTION}

Energy deficiency of Kaliningrad region compels to look for the ways of using non-traditional and renewable energy sources (NRES) in the regional energy balance. Among a lot of NRES' kinds in existence energy of biomass, wind energy, energy of small rivers, solar energy and low potential sources of heat will be able to make its considerable contribution in the energy balance in our regional conditions.

One of the potential renewable resources is biomass which includes wood waste from forestry activity, solid domestic waste and combustible industrial refuse, and wastes of animal husbandry, poultry breeding, fur farming and plant growing. Based on preliminary estimation, biofuel can replace more than 85,000 tons of equivalent fuel per year [1] in Kaliningrad region. Combined biofuel with other kinds of NRES will increase this value. Russian research $[2,3,4]$ and world practice $[4,5]$ confirms it.

\section{CATEGORIES OF OBJECTS}

Creation of autonomous heat power complexes (AHC) $[2,3]$ is presented. The transformation of NRES in different units and further use of received products has been 
realized. Such complexes need to be organized according to the objects which have large volume of organic waste materials, objects with potential ecological requirements and at autonomous objects (see Table 1).

Table 1. Categories of objects with autonomous heat power complexes in the region.

\begin{tabular}{lll}
\hline & Categories of objects & \\
\hline $\begin{array}{l}\text { Large-scale agroindustrial } \\
\text { complexes }\end{array}$ & $\begin{array}{l}\text { Schools and other } \\
\text { educational institutions }\end{array}$ & Individual farms \\
\hline Poultry factories & Sport centers & Suburban houses \\
\hline Fur farms & Sanatoriums & Public buildings \\
\hline Timber enterprises & Shopping centers & Settlements \\
\hline
\end{tabular}

The generalized scheme has been worked out for objects with AHC (see Figure 1). This scheme shows the structure and different categories of these objects' basics functioning.

At present time, the needs of these objects in electricity (E), heat energy (H) and water (W) are supplied with traditional resources. Among these resources are buying electricity (BE), heat energy from centralized heat supply systems $(\mathrm{CH})$, tap (TW) and artesian water (AW) and different fuels (F) such as black oil (FO), diesel fuel (FD), natural gas (FG), coal (FC) and peat (FP).

At the same time large-scale agroindustrial complexes, poultry factories and fur farms have large volume of organic waste materials with animal and vegetable origin which can be transformed by anaerobic fermentation to biogas and natural fertilizers (NF) in bioenergy units (BEU) [6, 7]. Combination of biogas units with wind energy turbines (WET), solar heating units (SHU) and heat pump units (HPU) will allow to completely refusing traditional fuel and energy resources' use at these objects.

Wood waste from forest economic activity of timber enterprises and of forest resources' use of logging enterprises and local population can be directly burned (DB) in bioenergy units or can be sold as pellets (PL) or briquettes after purification.

Solar heating units, wind energy turbines and heat pumps are possible to apply at sanatoriums, schools and other educational institutions, sport centers, shopping centers and public buildings. 


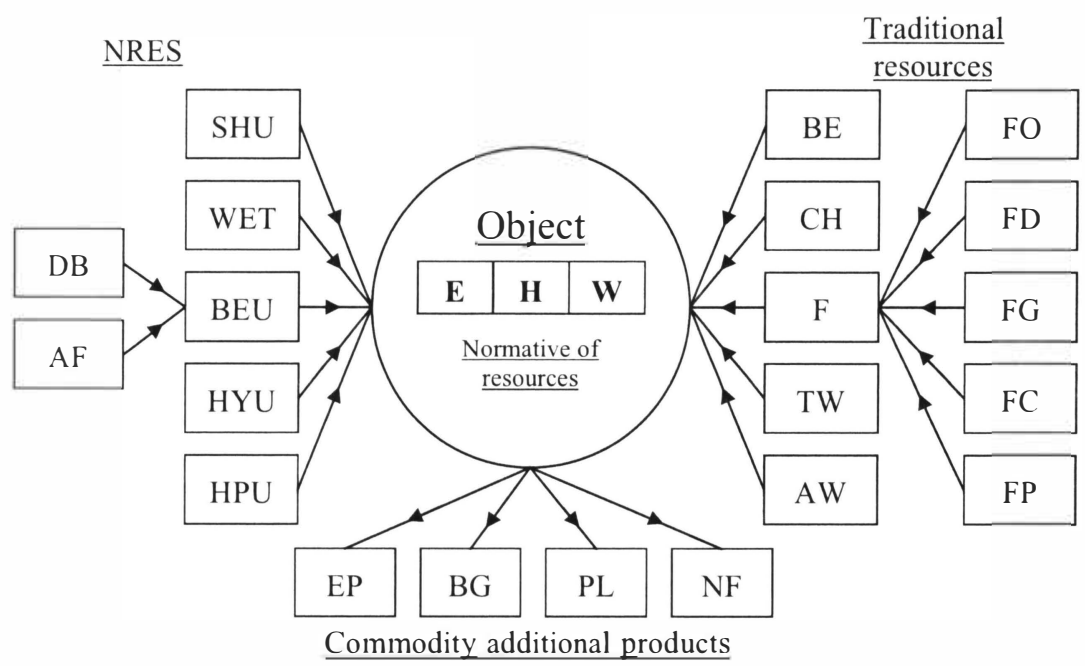

Figure 1. Structurally functional scheme of regional objects with $A H C$.

The joint using of biogas units, wind energy turbines, solar heater and heat pumps, completely autonomous water, fuel and energy supplying is possible at individual farms. A bioenergy unit will solve the problem of removal, disinfection and processing of organic waste materials forming at a farmstead. Biogas and pure liquid fertilizers will be produced during work of this unit. Biogas can be used for heating water for technological, own and domestic needs, for heating of living quarters and livestock barn, for cooking of meal and for preparation of feed to animals and poultry. A wind energy turbine will generate electricity for water raise from artesian well to fresh water tank and for satisfaction of the requirements of an individual farm. Solar heat and heat pump unit will be able to be applied for heat supply.

The same types of energy units as at individual farms can be used at suburban houses and settlements. Hydropower units (HYU) can be applied for electric power supply of all considered objects, but this is possible if small rivers or channels flow near autonomous heat power complexes.

Quite possible creation of autonomous heat power complexes with NRES will reduce consumption of traditional resources by substituting them by non-traditional energy sources, to receive an additional profit from realization of commodity products: electric power (EP), biogas, pellets and natural fertilizers and to improve ecological situation in the region.

\section{DISTRIBUTIONS OF LIVESTOCK}

Analysis of statistical data on livestock-breeding farms was also carried out. This statistical analysis is the basis of choice and calculation of structurally functional schemes of AHC. Average number of equivalent heads of cattle was determined on livestock of all age groups of cattle, pigs and horses of 139 livestock-breeding farms of Kaliningrad region. 


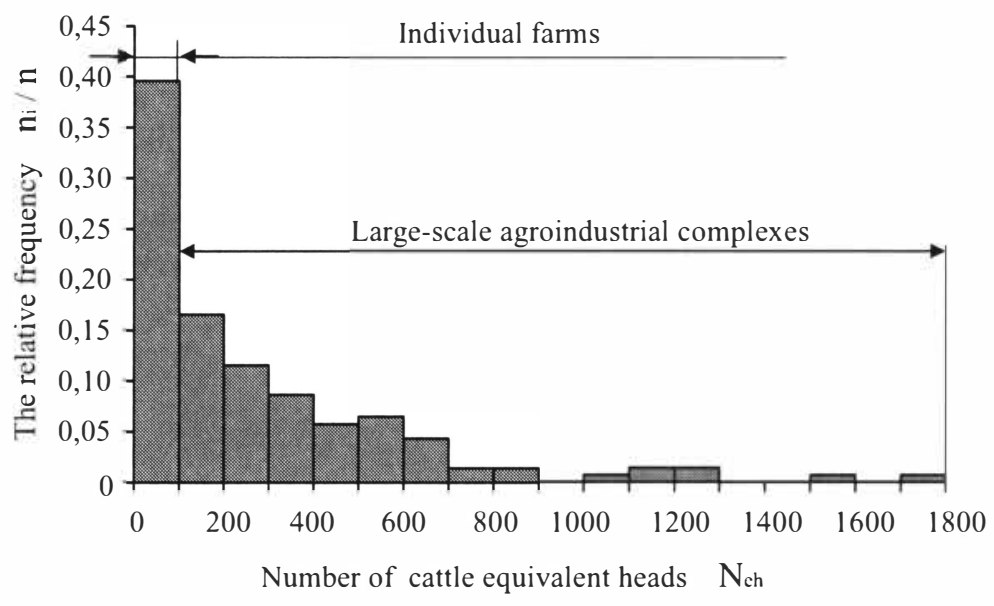

Figure 2. Histogram of livestock's distribution on livestock-breeding farms of Kaliningrad region.

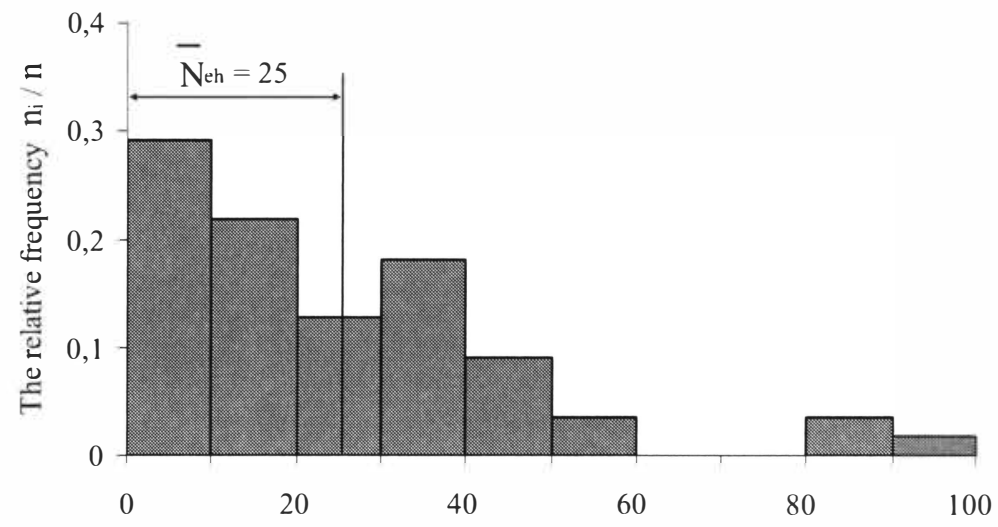

Number of cattle equivalent heads Neh

Figure 3. Histogram of livestock's distribution on individual farms.

One equivalent head of cattle is an animal which secrete $55 \mathrm{~kg}$ per day of excrement. In order to calculate the average number of equivalent heads of cattle, proportions between quantity of excrement of different kind and age groups of animals were used [4, 8]. Then all data was transformed into the grouped sample by using of methods of mathematical statistics [9]. The relative frequency of livestock-breeding farms' distribution on 18 grouping interval was 
determined for this sample. The histogram of livestock's distribution on regional livestockbreeding farms was plotted by results of calculation (see Figure 2).

Distribution of animals on regional farms has wide limits. In this connection the whole of $\mathrm{N}_{\mathrm{eh}}$ data range need to divide into two parts. The first part consists of individual farms where number of animals doesn't exceed 100 equivalent heads. Distribution of livestock on 55 individual farms is shown in the plotted histogram (see Figure 3). Average number of equivalent heads at this category of objects is 25 e.h..

The second part includes 84 large-scale agroindustrial complexes where number of animals is from 100 to 1800 equivalent heads. Average number of equivalent heads at this category is 450 e.h.. Distribution of livestock is shown in the plotted histogram (see Figure 4).

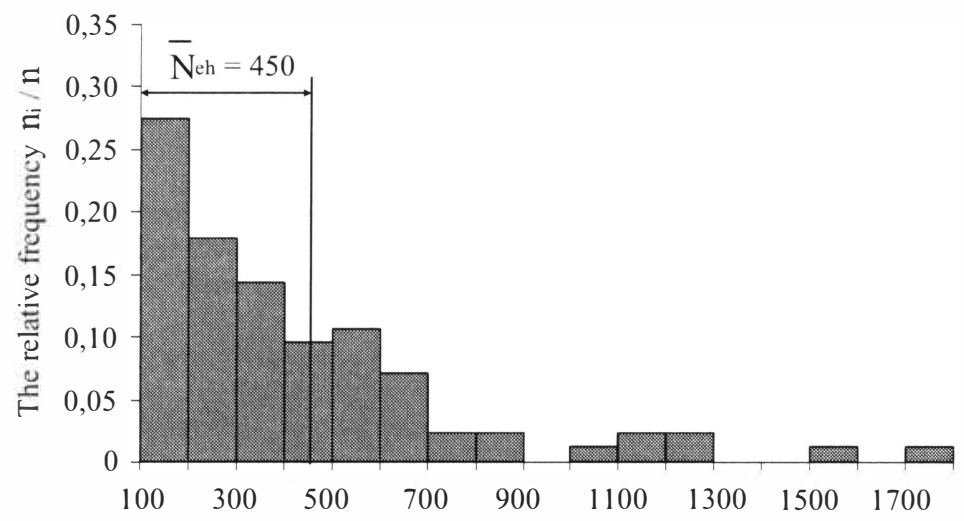

Number of cattle equivalent heads Neh

Figure 4. Histogram of livestock's distribution on large-scale agroindustrial complexes.

\section{CONCLUSIONS}

Definition of common potential of traditional energy resources substituted by means of comprehensive use of NRES at objects from Table $l$ and estimation of economic efficiency of this operation is one of the most actual regional tasks. The program of calculation of technical-and-economic indexes of different regional objects with AHC for the structurally functional scheme presented in Figure $l$ and for particular variants of this scheme is being carried out for solution of this task now.

The list of quantity and structure of regional objects with AHC have been determined as starting material for future calculation. Laws of distribution and average numbers of characteristic static parameters have been defined by using of mathematical statistics. This is shown by the example of livestock-breeding farms. 


\section{REFERENCES}

[1] Selin, V., Epishina, E., 2002. Analysis of using biofuel possibility in energy balance of the Kaliningrad region. Energy safety and small energetic. 21 century: materials of AllRussian scientific and technical conference, St.-Petersburg. 322-326.

[2] Ilin, A., Shishkin, N., 2004. Autonomous heat power complexes (structure, characteristics, efficiency). 112.

[3] Shishkin, N., 2000. Small power saving complexes with renewable energy sources. 236.

[4] Gujulev, E., Gorunov, V., Laptiy, A., 2004. Non-traditional renewable energy sources. Monograph. 272.

[5] Baader, W., Dohne, E., Brenndörfer, M., 1982. Biogas in theory and practice. 148.

[6] Pantshava, E., Pogarnov, V., Koshkin, N., 2002. Biomass is source of fuel and energy. Energy: economics, technique and ecology. 9, 21-25.

[7] Berkova, E., 2006. About possibility of creation of autonomous heat power complexes on a base of renewable energy sources. Electrica. 11, 18-19.

[8] Voroshilov, J., Durdibaev, S., Erbanova, L., 1991. Livestock-breeding complexes and preservation of the environment. 107.

[9] Chistyakov, V., 2003. Theory of probability's course. 272. 